\title{
¿PASA LA LEGITIMACIÓN DE LA PENA DE PRISIÓN EN UN SOCIEDAD DEMOCRÁTICA POR UNA POLITICA CRIMINAL REDUCCIONISTA?
}

\author{
LORENZO MORILLAS CUEVA \\ CATEDRÁTICO DE DERECHO PENAL \\ UNIVERSIDAD DE GRANADA (ESPAÑA) \\ Email: lorenzom@ugr.es
}

\begin{abstract}
Resumen: El objetivo principal del trabajo se centra esencialmente en el análisis de la realidad de la pena de prisión en la estructura punitiva actual. Para ello y con carácte general se sistematiza en varios niveles: por un lado, la valoración de las declaraciones internacionales más relevantes al respecto, su adecuación y seguimiento y las opiniones de la dogmática penal sobre la cuestión; por otro, en clave de datos estadísticos, su evolución hasta nuestros días, su eficiencia y eficacia en atención a la aplicación de dicha pena. Se llega de esta manera a resaltar las contradicciones entre expansionismo y reduccionismo y a la controvertida dicotomia de no fácil armonización, prevalente, por otra parte, con mayor o menor intensidad, en el panorama punitivo comparado como es la del aumento de la utilización de la pena de prisión versus búsqueda de nuevas formas alternativas a ella.
\end{abstract}

\begin{abstract}
The principle objective of this work focuses mainly on the analysis of the reality of prison punishment in the current punitive structure. To this end and with a general character, it is systemized on two levels: on one hand, the valuation of the most relevant international declarations regarding its adequacy and monitoring and the opinions of criminal dogma on this issue; on the other hand, with statistical data, prison punishment's evolution until the present day and its efficiency and effectiveness in response to the application of such punishment. This leads us to highlight the contradictions between expansionism and reductionism and the controversial dichotomy, which is not easy to harmonize, and is prevalent, furthermore, with greater or lesser intensity, in a compared punitive panorama, as is the increase in the use of prison punishment versus the search for new alternative forms to it.
\end{abstract}

Palabras clave: pena de prisión, expansionismo, reduccionismo, formas alternativas, estadisticas

Keyword: prison punishment, expansionism, reductionism, alternative forms, statistics

Sumario: I.- INTRODUCCIÓN. II.- VALORACIÓN INTERNACIONAL. III.- MARCO TEÓRICO VERSUS ESTADÍSTICO. IV.- A MANERA DE CONCLUSIÓN. 


\section{I.- INTRODUCCIÓN}

Bastante se ha escrito ${ }^{1}$, sobre todo en los últimos años, en torno a la pena de prisión desde las más diversas perspectivas, enfoques y realidades ideológicas, pero posiblemente una de las frases más afortunadas que sobre ella se han pronunciado y que pone de manifiesto su incidencia en la sociedad actual es la de que se trata de "un enfermo terminal con salud de hierro". Efectivamente son muchas las voces que han clamado por su desaparición o, al menos, por su mitigación como realidad punitiva, pero no han faltado, al mismo tiempo, impulsos dogmáticos y también, fundamentalmente, normativos de incremento en cuanto a su utilización.

Esta dicotomía entre lo pretendido y lo realizado ha llevado a severas disfuncionalidades en el ámbito punitivo y penitenciario. La casi obsesiva tendencia doctrinal, de la que formo parte, de plantear y desarrollar, en una búsqueda interminable pero absolutamente necesaria, una política criminal superadora de las contradicciones expansionistas-reduccionistas de la pena de prisión, conduce a notables aportaciones no bien entendidas por los órganos de poder y control social desubicados generalmente en una pretensión totalizadora de seguridad colectiva perturbadora, en demasiados casos, de los necesarios fines preventivos de la pena de prisión, de su pretensión reduccionista y de la coherente materialización de verdaderas alternativas a su excesiva aplicación.

Eso no quiere decir que se abandone la ya tradicional y, sin embargo, vigente idea de considerar a la susodicha pena como un importante mecanismo de control social que se asienta cuan criterio fundamentador en la pacífica convivencia de los ciudadanos y se legitima en su necesidad, "amarga necesidad" a la que la que se refirió el Proyecto Alternativo de Código penal alemán, de tanto éxito en la doctrina científica y de tan poca proyección en las normas positivas, incluidas las alemanas. Pero tampoco

\footnotetext{
${ }^{1}$ Yo mismo me he ocupado frecuentemente de este tema, entre otras: MORILLAS CUEVA, Lorenzo. Teoría de las consecuencias jurídicas del delito. Madrid, 1991, págs. 15 y ss. MORILLAS CUEVA, Lorenzo. "Valoración político-criminal sobre el sistema de penas en el Código penal español". Derecho Penitenciario II. En Cuadernos de Derecho Judicial. XVII, 2013, págs. 23 y ss. MORILLAS CUEVA, Lorenzo. "Alternativas a la pena de prisión". Derecho Penitenciario: incidencia de las nuevas modificaciones. En Cuadernos de Derecho Judicial. XXII. 2006. MORILLAS CUEVA, Lorenzo. "Pena de prisión versus alternativas: Una difícil convergencia". En Libertas. № 1-2013, págs. 450 y ss. MORILLAS CUEVA, Lorenzo. "La función de la pena en el Estado social y democrático de Derecho". En Revista Internacional de Doctrina y Jurisprudencia. Vol. 4. 2013.
} 
supone una asimilación de los estándares expansionistas tan proclives a los poderes constituidos.

En el ámbito internacional parece desprenderse de las múltiples resoluciones que tratan el tema una mantenida línea de consejos, no especialmente asumidos, de carácter reduccionista. Así, y remontándome en el tiempo a Concepción Arenal, ya en su Informe presentado al Congreso Penitenciario celebrado en San Petersburgo en 1890, aun dirigido en este aspecto a los presos preventivos, su contenido muestra una realidad ampliable a todos los internos en los Centro Penitenciarios del momento. Escribía la insigne penitenciarista que "la complicidad más directa en los delito, la más repugnante, la más atentatoria a la justica porque se ejerce en su nombre, es la acción depravadora de las prisiones; puesto que es costosa, difícil, obra de siglos, organizarlas como deben de estar, sería fácil suprimirlas en gran parte, si fácil fuera suprimir los errores y las preocupaciones" ${ }^{2}$. Semejantes duras palabras no exentas de cierta ingenuidad dialéctica estaban dirigidas a una auténtica reforma de las prisiones y del uso de la propia pena que presentaba una serie de ventajas que en opinión de la autora eran del máximo interés: a) no corromper en la cárcel evitando, además, la nota de infamia de haber estado preso; b) reducir los presos con lo que se podría reformar las cáceles de tal forma que tanto los edificios como el personal correspondieran a su objeto; c) las cárceles reformadas no serian depravadoras; d) las economías obtenidas serían grandes; e) la sociedad continuaría utilizando el trabajo de los presos en libertad; e) la familia de los procesados o condenados pero en libertad no se verían en la miseria ${ }^{3}$.

Deslizante con esta posición Concepción Arenal ya planteaba igualmente las necesarias alternativas en concreto a la penas de prisión de corta duración -las entendía como menores de un año- con las siguientes posibilidades: a) la amenaza, que consiste en notificar al procesado la pena en que ha incurrido cuya ejecución se suspende, pero que cumplirá muy agravada en caso de reincidencia; b) imposición de penas pecuniarias, siempre que se pueda en justicia; es decir, cuando el penado, dada la índole del delito tenga posibilidad de pagarlas, graduándolas según los casos; c) privación de ciertos derechos civiles y políticos y de ciertas ventajas, privación que ha de durar que

\footnotetext{
2 ARENAL, Concepción. Informes presentados en los Congresos Penitenciarios de Estocolmo, Roma, San Petersburgo y Amberes. 1ª ed., Fundación Biblioteca Virtual Miguel de Cervantes, 2012., pág. 157.

${ }^{3}$ Ibd., págs. $158-160$
} 
"debe durar por solo el tiempo de la pena suspendida"; d) que la pena pecuniaria se destine preferentemente a resarcir al perjudicado; e) que la protección de los Gobiernos a las sociedades de patronato para los que salen de prisión, conviene que sea más decidida con respecto a los penados que no han sido presos ${ }^{4}$.

Parece evidente y loable el sentido que la autora le da tanto al sistema penitenciario como a la utilización de la pena de prisión en una simbiosis que esclarece cuando llega a afirmar que "no es posible que el mejor sistema penitenciario de buenos resultados con leyes que cooperen al delito o a la pena con exceso e injusticia"5. Propuesta en la que los jueces y el procedimiento judicial a seguir tienen asimismo una especial trascendencia, que al no ser objetivo de este trabajo me impide extenderme con mayor intensidad en el pensamiento de la autora pero que quiero resaltar porque igualmente es relevante ${ }^{6}$ en cualquier propuesta al respecto.

Se preguntará el lector avezado que todavía tiene la paciencia de seguir este relato el por qué de semejante detenimiento en una autora del siglo XIX, en una cuestión de tanta actualidad y debate. Precisamente por eso, porque se determina la ya creciente controversia sobre la pena de prisión, de su fundamento, de sus alternativas, de su expansionismo, de su uso y ejecución. Es obvio que Concepción Arenal no fue la primera ni más obvio todavía la última que planteó estas cuestiones, pero si me sirve de

${ }^{4} I b d$., págs.. 173-176.

${ }^{5}$ Ibd., pág. 187.

${ }^{6}$ Concepción Arenal en su papel argumental asume que para la aplicación equitativa de la pena debe dejarse gran latitud al juez, a fin de que pueda sentenciar según las circunstancias individuales del acusado, y no sacrificarle a la letra de la ley. Ello como principio básico y de arranque es indiscutible para la autora, pero subordinado o mejor, completado con la idea que mayor poder necesita más "amor al bien y más conocimiento de la verdad, para que la libertad no degenere en arbitrariedad, necesita un juez muy recto y muy ilustrado". Y no siempre es así porque en muchos casos "suponiendo que sepan de leyes, desconocen al hombre que las infringe (...) La mayor extensión de conocimientos da mayor elevación de miras cuando ningún interés tiende a rebajarlas; da también tendencias más humanas. Esas rigidices férreas o cadavéricas de magistrados rectos, inflexibles e injustos, sin saberlo y sin quererlo, son generalmente hijas de la ignorancia. Con más conocimiento del hombre las sentencias (entiéndase bien, las sentencias, nos los jueces, a quienes no hacen la ofensa de calificar de inhumanos) se humanizarían" $I b d$., págs. 190-192. Afortunadamente nuestro sistema judicial actual, cierto es que con evidentes limitaciones, está lejano en este punto a tales precisiones y tipologías pero no es de más tener en cuenta y volver a reflexionar sobre el fondo de la cuestión planteada por la autora gallega. En relación con alguna de estas cuestiones véase mi opinión, por ejemplo, sobre el principio de legalidad y la discrecionalidad judicial en: MORILLAS CUEVA, Valoración...cit., págs. 53-61. Sobre la justicia en general desde la perspectiva penal: MORILLAS CUEVA, Lorenzo. "Algunas reflexiones sobre la justicia desde la visión de un penalista". En Foro FICP. № 2013.3 (diciembre), págs. 15 y ss. 
importante referencia para recorrer el iter argumental de la discutida presencia de semejante institución.

\section{VALORACIÓN INTERNACIONAL}

A nivel internacional, con más dudas que realidades, semejante línea interpretativa ha tenido sino éxito al menos cobertura importante. Así, desde Naciones Unidas se ha propiciado numerosas resoluciones al respecto fundamentalmente relacionadas con derechos humanos, o en las variables de derechos económicos, sociales, culturales, civiles y políticos en referencia a las personas privadas de libertad por ejemplo, el artículo 2 de la Declaración Universal de los Derechos Humanos, adoptada por la Asamblea General de Naciones, en Resolución 217 A de 10 de diciembre de 1948, fija que los Derechos proclamados en dicha Declaración afectan a todas las personas ${ }^{7}$ o el artículo 9 (interdicción de la arbitrariedad para ser detenido, preso o desterrado), 10 (igualdad, audiencia y justicia ante Tribunales independientes e imparciales en vía penal), 11 (presunción de inocencia, principio de legalidad en los delitos y en las penas), o, de parecida manera al susodicho artículo 2, el artículo 3 del Pacto Internacional de Derechos económicos, sociales y culturales (Asamblea General en su Resolución 2200 A (XXI), de 16 de diciembre de 1966, o el Pacto Internacional de Derechos civiles y políticos (Asamblea General en la Resolución 2200 A (XXI), de 16 de diciembre de 1966) que amplía considerablemente en cuanto a concreción y desarrollo los parámetros enunciados por los citados artículos 9, 10 y 11 de la Declaración. De especial interés para este trabajo es el artículo 10 en el que se señala expresamente el régimen penitenciario, la finalidad esencial de la ejecución de la pena de prisión, la necesaria separación entre procesados y condenados privados de libertad y de menores y adultos en tal situación ${ }^{8}$ - y que inciden con posterioridad en el principal

\footnotetext{
${ }^{7}$ Dice el artículo 2 en su número 1: "Toda persona tiene todos los derechos y libertades proclamados en esta Declaración, sin distinción alguna de raza, color, sexo, idioma, religión, opinión política o de cualquier otra índole, origen nacional o social, posición económica, nacimiento o cualquier otra condición". Por lo que cabe interpretar que en ese toda persona está incluida aquella que está privada de libertad, en relación con todos los demás derechos.
}

${ }^{8}$ Artículo 10: 1 . Toda persona privada de libertad será tratada humanamente y con el respeto debido a la
dignidad inherente al ser humano. 2 . a) Los procesados estarán separados de los condenados, salvo en
circunstancias excepcionales, y serán sometidos a un tratamiento distinto, adecuado a su condición de
personas no condenadas; b) Los menores procesados estarán separados de los adultos y deberán ser
llevados ante los tribunales de justicia con la mayor celeridad posible para su enjuiciamiento. 3. El
régimen penitenciario consistirá en un tratamiento cuya finalidad esencial será la reforma y la Universidad de Almería - Edificio Departamental de ${ }^{5}$ Ciencias Jurídicas - (Edif. D) Planta. 2, Despacho: 2.210 Ctra. Sacramento s/n - La Cañada de San Urbano 04120 Almería 
problema que se está analizando en esta reflexión, la propia realidad de la pena de prisión. Mas sin ser factores directamente reduccionistas de la mencionada pena sí ejercen como garantías de los ciudadanos que evitan su ingreso en prisión de manera discrecional y arbitraria, por lo que de esta forma se limita el uso, en tales hipótesis en sentido contrario, irracional, de la reiterada pena de prisión.

No obstante lo anterior, de gran importancia para el sistema penitenciario mundial y para el reconocimiento, en demasiadas ocasiones oscurecimiento cuando no destrucción, de las garantías y derechos de los internos en Centros Penitenciarios, también se pueden encontrar disposiciones que marcan la forma de entender la pena de prisión y su alcance, dibujando esa controvertida línea entre expansionismo y reduccionismo, objeto protagonista de esta obra.

En parecido sentido cobran especial protagonismo los diferentes Congresos de Naciones Unidas sobre prevención del delito y tratamiento del delincuente. El primero de ellos - Ginebra, 22 de agosto a 3 de septiembre de 1955-, por ejemplo, supone, en sus conclusiones y en la aprobación de "Reglas mínimas para el tratamiento de los reclusos" una importante guía de gran trascendencia mundial en torno a esta cuestión pues se ha desarrollado como una referencia básica en relación a la administración general de los establecimientos penitenciarias, en línea con las Declaraciones programáticas previas citadas. El segundo - Londres, de 8 al 19 de agosto de 1960,-, más relacionado con la cuestión que trato aunque igualmente impregnado de cuestiones penitenciarias, estuvo fundamentalmente dirigido a la delincuencia derivada de los cambios sociales consecuencia del rápido desarrollo económico, incluida la de menores. Entre sus muchas Recomendaciones cabe destacar la referida a las penas cortas privativas de libertad.

En dicha Recomendación, que ya actúa sobre un discutible núcleo de la pena de prisión, se plantean dos importantes bloques: por un lado, el estudio mismo de tal pena de corta duración, su vigencia y eficacia - contagio moral debido a la influencia

readaptación social de los penados. Los menores delincuentes estarán separados de los adultos y serán sometidos a un tratamiento adecuado a su edad y condición jurídica. 
corruptora de la promiscuidad con criminales con penas de media o larga duración, efecto correctivo o intimidatorio inexistente, falta de valor educativo-; por otro, medios de sustitución en ese momento utilizados y propuestas de futuro. En tal sentido la Recomendación no deja de ser titubeante en sus planteamientos al partir de la idea de que aun aceptando la fuerte contestación a la pena de prisión de corta duración su supresión total sería difícil, lo que no empece "la conveniencia de sustitución por otras penas que no tengan los efectos nocivos que a menudo se le atribuyen a las penas cortas de privación de libertad". Sobre semejantes argumentaciones de manera conclusiva afirma, en una valoración que parece, al menos a mí me lo sugiere, excesivamente relativista, aunque hay que tener en cuenta el momento cronológico en que se produce, lo siguiente: a) la pena corta privativa de libertad, especialmente la muy corta, debería evitarse en todo lo posible, pero no abolirse totalmente; b) la pena corta no debería aplicarse en una forma general, sino en los casos concretos en los que haya de resultar eficaz por la razón de las circunstancias, sean personales o de otra índole y en caso de imposición, el condenado debería ser enviado de preferencia a un establecimiento abierto o semiabierto o especial para esta clase de reclusos y, en todo caso, separado, de los otros penados; c) tales penas, en la medida de lo posible, debería reemplazarse por otras sanciones o medidas no privativas de libertad -se enumeran, a título de ejemplo no como únicas, hasta dieciséis; d) la ejecución de estas sanciones o medidas debería tener la mayor flexibilidad posible, siempre que sea compatible con la finalidad de la pena. Como puede observarse se está ante un documento que, a pesar de sus limitaciones y dudas, mantiene abierto un camino de especial trascendencia para la valoración utilitarista de la pena de prisión, aunque únicamente sea de la de corta duración e, incluso, dentro de ella de las más recortadas conceptualmente.

En este planteamiento de ejemplos puntuales cabe pasar al sexto Congreso 9 Caracas, del 25 de agosto a 5 de septiembre de 1980- en el que sin entrar en estimación valorativa de la pena de prisión o de sus posibles alternativas, el marco temario sobre el que se desarrolló, bajo la nominación de "la prevención del delito y la calidad de vida", fue precisamente las previsiones de dicha prevención basada en las circunstancias

\footnotetext{
${ }^{9}$ El tercero - Estocolmo, del 9 al 18 de agosto de 1965- analizó las relaciones entre la delincuencia y la evolución social; El cuarto - Kyoto, del 17 a 26 de agosto de 1970- trató sobre mejor planificación de la prevención del delito para el desarrollo económico y social; en el quinto - Ginebra, del 1 al 12 de septiembre de 1975- se aprobó la Declaración sobre la protección de todas las personas contra la tortura y otros tratos o penas crueles, inhumanas o degradantes-.
} 
sociales, culturales, políticas y económicas del país antes que en las represivas punitivas. Así lo destaca en el Informe, en apoyo de la Declaración de Caracas, en cuyo punto 1 se declara que "el éxito de los sistemas de justicia penal y de las estrategias para la prevención del delito, especialmente en vista del aumento de nuevas y sofisticadas formas de delincuencia y las dificultades que enfrenta la administración de justicia penal, depende ante todo de los progresos que se realicen en el mundo para mejorar las condiciones sociales y para elevar el nivel de calidad de la vida, de esta manera resulta indispensable revisar las estrategias tradicionales para combatir el delito basadas exclusivamente en criterios jurídicos".

Sí se plantea con mayor intensidad la función de la pena y la promoción de sanciones no privativas de libertad como alternativas en el octavo Congreso ${ }^{10}$ - La Habana, 27 de agosto a 7 de septiembre, de 1990- en el que se aprueban normas, entre otras referidas a reglas mínimas de las Naciones Unidas para las medidas no privativas de libertad. En el Informe provisional del Secretario General que luego daría lugar a la propuesta del Congreso a la Asamblea General de Reglas mínimas para las medidas no privativas de libertad se parte de la base de que pese a los esfuerzos encaminados a disminuir la aplicación y presencia de la pena de prisión ésta sigue siendo la piedra angular de los sistemas penales actuales, lo que no oculta las numerosas desventajas de la prisión, tanto para el delincuente como para la sociedad por lo que a nivel mundial y de las instituciones internacionales se procura encontrar medidas sustitutorias no privativas de libertad que han de ser sanciones sin privación de libertad "fiables". Este último es el objetivo en torno a este tipo de penas elaborado en el susodicho Congreso y que supone un paso importante en esa especial dicotomía entre pena de prisión y alternativas no privativas de libertad.

Sobre semejante previsión congresual se eleva el documento a la Asamblea de Naciones Unidas que en Resolución 45/110, de 14 de diciembre de 1990 aprueba las reiteradas Reglas mínimas de Naciones Unidas sobre medidas no privativas de libertad (Reglas de Tokio) en las que se proclaman como objetivos fundamentales los

\footnotetext{
${ }^{10}$ El séptimo Congreso - Milán, del 26 de agosto al 6 de septiembre de 1985- complementa el anterior sobre la Prevención del delito para la libertad, la justicia, la paz y el desarrollo, con aprobación de instrumentos como reglas mínimas para la administración de la justicia de menores o los principios básicos relativos a la independencia de la justicia o el Acuerdo sobre el traslado de reclusos extranjeros y recomendaciones.
} 
siguientes: a) concreción de una serie de principios básicos para promover la aplicación de medidas no privativas de libertad, así como salvaguardias mínimas para las personas a quienes se aplican medidas sustitutivas de la prisión -opción descriptiva donde se diseña la idea de utilización de medidas diferentes a las penas privativas de libertad junto a un desarrollo garantista en relación al individuo ${ }^{11}-$; b) fomentar una mayor participación de la comunidad en la gestión de la justicia penal, especialmente en lo que respecta al tratamiento del delincuente, así como incrementar entre estos el sentido de su responsabilidad hacia la sociedad -intento de combinar dos premisas básicas en el desarrollo de la respuesta penal: integración social con responsabilidad de los sujetos que cometen delitos en su relación con la sociedad-; c) aplicación teniendo en cuenta las condiciones políticas, económicas, sociales y culturales de cada país, así como los propósitos y objetivos de su sistema de justicia penal -respeto a la soberanía de cada país, pero sobre las bases anteriormente fijadas-; d) por otro lado, y en el objetivo 4, se alerta a los Estados Miembros para que se esfuercen por alcanzar un equilibrio adecuado entre los derechos de los delincuentes, los derechos de las víctimas y el interés de la sociedad en la seguridad pública y la prevención del delito -trilogía a conseguir esencial para mantener una adecuada ponderación entre las tres partes intervinientes en un conflicto punitivo-; e) como, consecuencia de lo anterior, y en el 5 objetivo, se fija que los Estados Miembros introducirán medidas no privativas de la libertad en sus respectivos ordenamientos jurídicos para proporcionar otras opciones, y de esa manera reducir la aplicación de las penas de prisión, y racionalizar las políticas de justicia penal, teniendo en cuenta el respeto de los derechos humanos, las exigencias de la justicia social y las necesidades de rehabilitación del delincuente -parámetros esenciales que resumen con precisión la tendencia y objetivos claves de Naciones Unidas al respecto12

\footnotetext{
11 El punto 8.2 de las Reglas especifica las siguientes medidas: a) sanciones verbales, como la amonestación, la reprensión y la advertencia; b) libertad condicional; c) Penas privativas de derechos o inhabilitaciones; d) Sanciones económicas y penas en dinero como multas y multas sobre los ingresos calculados por días; e) Incautación o confiscación; f) Mandamiento de restitución a la víctima o de indemnización; g) Suspensión de la sentencia o condena diferida; h) Régimen de prueba y vigilancia judicial; i) Imposición de servicios a la comunidad; j) Obligación de acudir regularmente a un centro determinado; k) Arresto domiciliario; 1) Cualquier otro régimen que no entrañe reclusión; m) Alguna combinación de las sanciones precedentes. Incluso se alude en el punto 9.2 a la aplicación de medidas posteriores a la sentencia como: permisos de salida y centros de transición, liberación con fines laborales, distintas formas de libertad condicional, remisión, indulto.
}

12 Sorprende, no obstante, la amplitud con que en el número 2 se señalan a las personas a las cuales se aplicarán las susodichas reglas, que son las sometidas a acusación, juicio o cumplimiento de una 
Han transcurrido veinticuatro años desde la mencionada fecha en la que Naciones Unidas formuló las reiteradas Reglas Mínimas y los documentos previos en los que se situaba el amplio debate sobre la pena de prisión y sus posibles alternativas no privativas de libertad, con interesantes propuestas que han incidido de manera desigual en los Ordenamientos internos de los países miembros, y la realidad práctica y normativa sigue siendo parecida con una utilización importante y, en la mayoría de los casos, prioritaria de la pena de prisión. Cierto es que los posteriores Congresos y otras declaraciones de Naciones Unidas ${ }^{13}$ han profundizado sobre el tema, más en la concreción de nuevas formas de delincuencia, de respuestas a las exigencias de adaptación social de la prevención delictiva y, en el ámbito estrictamente relacionado con la prisión, con especial atención a los mecanismos y garantías penitenciarias. De destacar, en este último sentido, el $11^{\circ}$ Congreso -Bangkok, del 18 al 25 de abril de 2005- en cuya Declaración nominada como la ciudad sede, presta concreta atención no solo al sistema penitenciario -“30. Recomendamos que la Comisión de Prevención del Delito y Justicia Penal considere la posibilidad de revisar la idoneidad de las reglas y normas en relación con la administración penitenciaria y los reclusos"- sino también incluso a las bondades de una novedosa justicia restaurativa que influya en la previsión reduccionista de la pena de prisión - “32. Para promover los intereses de las víctimas y la rehabilitación de los delincuentes, reconocemos la importancia de seguir elaborando políticas, procedimientos y programas en materia de justicia restaurativa que incluyan

sentencia, en todas las fases de la administración de las justicia penal, lo cual lleva a designar "delincuentes", a los efectos de las Reglas a estas personas "independientemente de que sean sospechosos o de que hayan sido acusados o condenados". Complicada identificación entre esta trilogía de posibilidades procesales a efectos de aplicación de estas penas o medidas alternativas, que evidentemente son más apropiadas, en la mayoría de los casos, que la privación de libertad.

${ }^{12}$ Así, por ejemplo, el $9^{\circ}$ Congreso -El Cairo del 28 de abril a 5 de mayo de 1995- bajo el slogan "Menos crimen, más justicia: seguridad para todos" se centró esencialmente en la cooperación internacional y en la asistencia técnica de carácter práctico para fortalecer el imperio de la ley, con temas como "Sistemas de justicia penal y de policía" "Medidas contra la delincuencia organizada y transnacional". El $10^{\circ}$ Viena del 10 al 17 de abril de 2000- aprobó la Declaración de Viena sobre medidas contra la corrupción en el plano internacional, en cuyo Manifestación número 22 reconoce, entre otras, la importancia del sistema penitenciario. 
alternativas del juzgamiento, a fin de evitar los posibles efectos adversos del encarcelamiento, de ayudar a reducir el número de causas que se presentan ante tribunales penales y de promover la incorporación de enfoques de justicia restaurativa en las prácticas de justicia penal, según corresponda"-.

De especial interés en la línea que nos ocupa es el último de los Congresos celebrados hasta la fecha de este escrito -Salvador de Bahía (Brasil), del 12 al 19 de abril de 2010- por la atención que le presta a estas cuestiones en la importante Declaración de Salvador sobre "Estrategias amplias ante problemas globales: los sistemas de prevención del delito y justicia penal y su desarrollo en un mundo en evolución" avalada con posterioridad por la Resolución de la Asamblea General de Naciones Unidas de 21 de diciembre de 2010. Cinco variables de diferente naturaleza, algunas son meros proyectos de estudio, son proclamadas en el texto: a) reconocimiento del sistema penitenciario como uno de los elementos principales del sistema de justicia penal y en consecuencia utilización de las reglas y normas de la propia Naciones Unidas para el tratamiento de los reclusos como fuente de orientación a fin de elaborar o actualizar los códigos nacionales de administración penitenciaria; b) revisión de las reglas mínimas de Naciones Unidas para el tratamiento de los reclusos con el objetivo de reflejar en ellas los recientes avances de la ciencia penitenciaria; c) atención especial a las medidas de tratamiento de las mujeres detenidas y sometidas a medidas privativas o no privativas de libertad; d) necesidad de reforzar las medidas sustitutivas de la prisión, como pueden ser, el servicio comunitario, la justicia restaurativa y la vigilancia electrónica, así como apoyar programas de rehabilitación y reinserción y los destinados a corregir las conductas delictivas y los programas de educación y formación profesional para los reclusos; e) limitar, cuando corresponda, el recurso a la prisión preventiva $^{14}$.

De todo lo expuesto, con la brevedad necesaria en un escrito de estas características, puede deducirse como primera valoración positiva el interés de Naciones Unidad, al menos inicialmente, por estas cuestiones de vital importancia para el propio sistema interno e internacional de Justicia penal. Y ello lo afirmo porque son indicadores, no especialmente profundos cierto es, del camino a seguir para una adecuada política criminal garantista y protectora de los principios básicos que han de

\footnotetext{
${ }^{14}$ Números 48 a 52 de la Declaración.
} 
marcar los fines de la pena en general y de las alternativas a la de prisión en particular en un Estado social y democrático de Derecho con las ingentes variables con que pueden desarrollarse en el derecho positivo local de tan diversos componentes y sistemas políticos y jurídicos del catálogo de Estados que constituyen la Institución: respeto a los derechos esenciales de los penados a los que se les aplique una pena alternativa; participación de la sociedad en la realización de la justicia penal para de esta forma incrementar su comprensión por semejantes opciones; combinación de la dicotomía, a veces difícil de conseguir y comprender, entre seguridad y prevención de delito con formas más imaginativas y adecuadas que la pena de prisión, lo que conduce a una conveniente y necesaria ponderación entre derechos de los penados o imputados, víctimas e intereses sociales; políticas de justicia penal adecuadas a tales objetivos, reduccionismo de la pena de prisión, respeto a los derechos humanos de los condenados, atención a las demandas de justicia social y los objetivos de resocialización.

La atención de Naciones Unidas a estas cuestiones se bifurca en una serie de Acuerdos, Recomendaciones, Consideraciones, Informes, Reglas, a veces muy repetitivas, excesivamente formalistas y que, posiblemente, no encaren el problema nuclear de la pena de prisión con toda la intensidad a desear desde una perspectiva minimalista y no expansionista de tal sanción penal. Dos son las perspectivas desde las que se parte. Por un lado, planificar estrategias generales para reducir el ámbito del sistema de justicia penal y evitar de tal forma e indirectamente el uso del encarcelamiento; b) plantear la utilización de medidas sustitutivas en todas las fases del sistema de justicia penal, que cabe concretarlas en tres: a') fase anterior al juicio basadas fundamentalmente en actuaciones prejudiciales y a evitar, en la medida de los posible, los efectos nocivos de la prisión preventiva ${ }^{15}$; b') fase de la sentencia -es posiblemente la más destacada en la que se intensifican las posibilidades de evitar la

15 Cuestión ésta tratada con cierta frecuencia en las propuestas internacionales. Como resumen ejemplificativo destacar como hipótesis alternativas: comparecer ante un Tribunal en un día concreto o según lo que ordene el Tribunal en el futuro; abstenerse de interferir en el curso de la justicia, incurrir en una conducta determinada, ir, o no ir, a determinados lugares o zonas, o aproximarse a personas concretas o reunirse con ellas; permanecer en una dirección específica; presentarse diariamente o de forma periódica ante un tribunal, la policía u otra autoridad; entregar el pasaporte u otros documentos de identificación; aceptar la supervisión de un organismo de someterse a vigilancia electrónica; o entregar fondos u otros tipos de propiedad como garantía de que comparecerá ante el juez en el momento del juicio, o que mantendrá una conducta determinada mientras éste no se celebre. 
prisión, sobre un cuadro interesante de supuestos ${ }^{16}$; c') fase de carcelación/excarcelación anticipada de los reclusos sentenciados y privados de libertad -se combinan las hipótesis de permanencia en prisión, las más tratadas desde la perspectiva del derecho penitenciario tan frecuentemente considerado en las proclamaciones de Naciones Unidas, con las de apertura gradual a la libertad del penado, a veces, con cierta confusión conceptual al combinar lo que son permisos penitenciarios, verdaderas alternativas de libertad, como la remisión sin condiciones, o simples causas de extinción de la responsabilidad penal ${ }^{17}$-.

Con semejante perspectiva el susodicho Manual, asimismo a manera de síntesis reflexiva de las diversas propuestas de Naciones Unidas al respecto, afirma como explicación a la posible utilización de medidas alternativas varios supuestos a tener en cuenta: a) el encarcelamiento como forma de castigo cabe ser mostrado como ajeno a las tradiciones culturales locales de ciertos países que durante milenios han recurrido a formas alternativas de combatir el delito; b) parece demostrado, por otro lado, que semejante privación de libertad puede ser contraproducente si se pretende rehabilitar y reinsertar a los condenados a delitos menores así como para determinados grupos vulnerables de la población ${ }^{18}$.

Estas dos parciales afirmaciones sustitutivas de la pena de prisión chocan con la realidad práctica no solo de un observador objetivo sino también de Naciones Unidas al

\footnotetext{
${ }^{16}$ Destacar entre ellos: sanciones verbales, como la amonestación, la reprensión y la advertencia; libertad condicional; penas privativas de derechos o inhabilitaciones; sanciones económicas y penas en dinero, como multas y multas sobre los ingresos calculados por días; incautación o confiscación; mandamiento de restitución a la víctima o de indemnización; suspensión de la sentencia o condena diferida; régimen de prueba y vigilancia judicial; imposición de servicios a la comunidad; obligación de acudir regularmente a un centro determinado; arresto domiciliario; cualquier otro régimen que no entrañe reclusión; alguna combinación de las sanciones precedentes.
}

${ }^{17}$ Se refieren fundamentalmente desde la suavización del régimen carcelario para permitir que el recluso tenga un contacto limitado con la sociedad aplicándole un régimen de libertad condicional en la comunidad, hasta las libertades anticipadas sin condiciones: permisos y centros de transición, liberación con fines laborales o educativos, distintas formas de libertad condicional, remisión, indulto. En esencia en las Reglas de Tokio -Asimismo en el Manual de principios básicos y prácticas prometedoras en la aplicación de medidas sustitutivas al encarcelamiento (Naciones Unidas, Nueva York 2010, pág. 2 y 31 a 66- en adelante Manual-) se diferencian estas tres hipótesis de actuación. Vid, con amplitud: MORILLAS CUEVA, Lorenzo. "Aspectos generales de la pena de prisión. Alternativas y sustitutivos". En La aplicación de las alternativas a la pena de prisión en España. Dir: Morillas Cueva-Barquín Sanz. Ed. Defensor del Pueblo. Madrid, 2013, págs. 34-40.

${ }^{18}$ Manual...cit., pág. 3. 
aseverar el mismo Manual que en todo el mundo se recurre cada vez más al encarcelamiento como forma general de castigo, "aunque hay pocas pruebas de que su mayor utilización mejore la seguridad pública"19, lo que provoca en demasiadas ocasiones graves problemas de hacinamiento y conculcación de las normas básica de Naciones Unidas y otras que exigen un trato de respeto a la dignidad y a los valores inherentes de su condición de seres humano para los reclusos, es decir, a los derechos humanos de todos los ciudadanos sea cual sea su situación.

La situación en la Unión Europea es parecida, aunque tiene la ventaja inicial de una mayor homogeneidad de los países miembros, de los fines a conseguir y de los modelos de Estado compartidos. Tanto es así que se habla de una auténtica vertebración del nuevo Espacio Penitenciario Europeo que va bastante más allá de un simple sistema de traslado de personas condenadas y en la que la política criminal en relación a las penas, y en concreto a las privativas de libertad, ha querido evolucionar hacia una conciencia, relajada desde mi punto de vista, de humanización de dichas penas sobre los cimientos de actuar en razón a parámetros de sustitución de la prisión o de previsiones condicionales de condenas o de libertades, en la idea final de utilizar lo menos posible la prisión. Mas, como dice con buen criterio Baras González, parece, como, según él, queda demostrado -nosotros afrontaremos dicha demostración páginas más adelante-, las reformas penales de los veinte últimos años llevadas a cabo en los Códigos penales europeos ponen de manifiesto un evidente alejamiento de semejante pretensión programática $^{20}$.

Interesante es, como planteamiento previo a la materia que estamos analizando, resaltar los esfuerzos comunitarios, inacabados, para conseguir una auténtica cooperación judicial que articule las medidas y propuestas más adecuadas para hacer frente a la delincuencia internacional incentivada por la necesaria mayor libertad que la proclamada movilidad europea produce en su versión negativa. Necesidad para la Unión de garantizar la protección en clave de seguridad para los ciudadanos europeos, para las víctimas de los delitos y la atención a los sujetos que cometen delitos ${ }^{21}$. En tal

${ }^{19} \mathrm{Ibd}$.

${ }^{20}$ BARAS GONZÁLEZ, Marcos. El espacio penitenciario europeo. Madrid, 2013, pág. 210.

${ }^{21}$ En este sentido, en la ficha Técnica sobre cooperación judicial en materia penal se estructura como resultados de semejante objetivo los desarrollados en: A) marco institucional (Tratado de Lisboa -más efectividad, responsabilidad y legitimidad en el espacio de libertad, seguridad y justicia-, Programa de 
línea es de mencionar sobre un enfoque de la UE acerca del derecho penal de la Comisión de libertades civiles, justicia y asuntos del interior, la Resolución del Parlamento Europeo de 12 de abril de 2012 (A7-0144/2012)en la que se marcan principios tan importantes para la comprensión del sistema de penas como el de respeto pleno a los derechos fundamentales de las personas sospechosas, acusadas o condenadas, el de proporcionalidad entre la pena y la infracción penal cometida, culpabilidad, seguridad jurídica, irretroactividad y de lex mittior, non bis in idem, presunción de inocencia, intervención mínima referido tanto a los delitos como a las penas.

En concreto el sistema europeo penitenciario y, en especial, a los efectos de este trabajo, en relación a la pena de prisión y al encarcelamiento como consecuencia de ésta, se asienta sobre una larga tradición individualizada y colectiva, nacida de manera relevante con la Ilustración ${ }^{22}$. En la actualidad, en la entrada del siglo XXI, está orientado por múltiples Recomendaciones del Comité de Ministros del Consejo de Europa a través fundamentalmente del Comité Europeo en Problemas Criminales y el Consejo para la Cooperación Penológica, Resoluciones de la Comisión y del Tribunal Europeo de Derechos Humanos, Decisiones Marco del Consejo de la Unión Europea, tales como Decisión Marco 2005/214/JAI, 24 febrero 2005, relativa a la aplicación del principio de reconocimiento mutuo de sanciones pecuniarias, Decisión Marco 2008/909/JAI, 27 noviembre 2008, relativa a la aplicación del principio de reconocimiento mutuo de sentencias en materia penal por las que se imponen penas $u$ otras medidas privativas de libertad a efectos de su ejecución en la Unión Europea, Decisión Marco 2008/947/JAI, 27 noviembre 2008, relativa a la aplicación del

Estocolmo - nuevo programa plurianual para el periodo 2010-2014, en el marco del espacio de libertad, seguridad y justicia-), B) Asistencia judicial mutua en materia penal; C) Reconocimiento mutuo de las resoluciones judiciales en materia penal; D) Orden de detención europea; E) Aproximación dee las legislaciones; F) Eurojust, Red Judicial Europea y los equipos conjuntos de investigación; F) Derechos procesales; H) Hacia una política de Derecho Penal de la UE. "La cooperación judicial en materia penal". Fichas técnicas sobre la Unión Europea. 2015. Alessandro Davoli, 04/2014.

${ }^{22}$ SNACKEN, Sonja- VAN ZYL SMIT, Dirk señalan que en dicho periodo, en el que el objetivo de la pena pasó de ser el causar dolor de manera arbitraria, a una más deliberada corrección de los condenados, la pena de prisión resultó, por vez primera, un elemento clave del castigo, impulsadas las nuevas orientaciones, -que, según mi opinión, en todo caso no dejaron de ser correccionalista-retribucionistas-, de la mano de comprometidos penitenciaristas como Howard, entre otros. VAN ZYL SMIT, DirkSNACKEN, Sonja Principios de derecho y politica penitenciaria europea. Penología y derechos humanos. Valencia 2013, pág.32. 
principio de reconocimiento mutuo de sentencias y resoluciones de libertad vigilada con miras a la vigilancia de las medidas de libertad vigilada y las penas sustitutivas, Decisión Marco 2009/829/JAI, de 23 de octubre 2009, relativa a la aplicación, entre Estados miembros de la Unión Europea, del principio de reconocimiento mutuo a las resoluciones sobre medidas de vigilancia como sustitución de la prisión provisional ${ }^{23}$.

Todas ellas, y otras más que se podrían citar como Decisiones, Recomendaciones, etc., marcan criterios, sobre los fundamentos antes esbozados, acerca esencialmente, como también pasa con las propuestas de Naciones Unidas, de la aplicación de la pena de prisión y de los aspectos penitenciarios de semejante cuestión sin obviar referencias a posibles alternativas y a los principios que deben ser limitadores del uso excesivo de semejante reacción penal y que no siempre $\mathrm{y}$ en todas las circunstancias cumplen dicho objetivo.

Se detecta, pues, fundamentalmente, la pretensión de regularización de los diversos sistemas de los países miembros sobre denominadores compartidos en la idea del espacio común europeo en relación a las justicia penal, posiblemente más formalista que valorativa de las verdaderas exigencias de la realidad punitiva volcada hacia un expansionismo de bienes jurídicos a proteger, de delitos a sancionar y de utilización excesiva de la pena de prisión, a pesar de los planteamientos protectores de los derechos humanos de los penados y de la orientación de encuentro y cooperación entre las legislaciones internas o precisamente por ello. Sin embargo, y a pesar de esta apreciación genérica de la situación, algunos autores han fijado con mayor optimismo o posiblemente objetividad de las tendencias europeístas sobre tal trilogía y en lo que a este escrito atañe a la pena de prisión.

Así, Cid, ha resumido los principios básicos de la política criminal europea en materia de sanciones y alternativas a la prisión sobre dos relacionados intrínsecamente entre sí y que son soporte, al menos teórico, de semejante manifestación : por un lado, la prisión como última ratio en el sistema de sanciones - diversificado en dos orientaciones; a) la pena de prisión únicamente debe adoptarse cuando la gravedad de la

23 Para más detalle vid, entre otros: GRUPO DE ESTUDIOS DE POLÍTICA CRIMINAL. "Una propuesta alternativa al sistema de penas y su ejecución, y a las medidas cautelares personales. Anexos". Documentos del Grupo. Málaga 2005, págs. 91-297. VAN ZYL SMIT, Dirk-SNACKEN, Sonja Principios...cit., págs.. 42 y ss. 
conducta haga inapropiada cualquier otra sanción; b) la pena de prisión sólo es admisible cuando ninguna otra pueda alcanzar el objetivo de la rehabilitación ${ }^{24}$-; por otro, las sanciones alternativas a la prisión han de ser la respuesta frente a la comisión del delito, asentadas sobre dos ideas; una, respeto a la libertad de la persona y evitar los efectos negativos del encarcelamiento; dos, están en mejores condiciones que la pena de prisión de conseguir las finalidades del castigo ${ }^{25}$.

El aceptable y pretendido equilibrio en la política criminal europea entre pena de prisión y alternativas a ella se me antoja más una declaración programática que un análisis detallado de las consecuencias e inoportunidad del uso desmesurado de aquella, pues la orientación nuclear de la programación europea al respecto no deja de mantener la dicotomía seguridad-pena de prisión con evidente tendencia hacia la dureza y frecuencia de ésta. Esclarecedora al respecto es la opinión del ponente, Cornelis de Jong, del Informe antes citado "sobre un enfoque de la UE acerca del Derecho penal" en cuya Exposición de Motivos, en clave ya de texto del Parlamento Europeo se alude de la siguiente manera: "Las disposiciones de Derecho penal se proponen con demasiada facilidad debido a sus supuestos efectos simbólicos y disuasorios: tratan de tranquilizar a los ciudadanos europeos convenciéndoles de que la UE se toma en serio su seguridad y de dejar claro a los delincuentes potenciales que recibirán un severo castigo. Pero, en realidad, no es una disposición del Derecho penal en sí misma la que da lugar a una reducción de la delincuencia en la UE. La ejecución de las sanciones es igual de importante, si no lo es más; el mero hecho de que la UE haya adoptado una nueva legislación no hace que disminuya la cantidad de delincuencia. Solo si las disposiciones jurídicas son claras y se corresponden con los sistemas nacionales existentes, la ejecución podrá ser eficaz. Es la combinación de la existencia de disposiciones de Derecho penal y de su cumplimiento lo que normalmente incide en la delincuencia”. Al margen de las disfuncionalidades conceptuales que tal manifestación presenta visualiza un derecho penal más simbólico que práctico, con prevalencia de la prevención general, con programación de duras sanciones y con la exigencia de una eficaz ejecución.

\footnotetext{
${ }^{24} \mathrm{Cid}$ los estima como dos fundamentos distintos del reduccionismo: el modelo punitivo proporcionalista en el primer caso y el modelo rehabilitador en el segundo. CID, José. "La política criminal europea de sanciones alternativas a la prisión y la realidad española: una brecha que debe superarse". En Estudios Penales y Criminológicos. Vol. XXX (2010), págs. 60-61.

${ }^{25}$ Ibd., pág. 62.
} 


\section{III.- MARCO TEÓRICO VERSUS ESTADISTICO}

No cabe negar que si únicamente se atiende a la declaración de principios básicos por los que ha de transcurrir la pena de prisión y el derecho penitenciario a nivel mundial y europeo las respuestas de Naciones Unidas y de la Unión Europea pueden calificarse, en términos generales, de aceptables incluso, como hacen Van Zyl SmitSnacken, de mostrar una cierta política reduccionista basada en el principio del encarcelamiento como última medida que, sin embargo, su aplicación a nivel interno es bastante más problemática ${ }^{26}$ por la tendencia a un expansionismo creciente en las normas nacionales. De este modo lo ve un amplio sector de la doctrina que manifiesta su preocupación por lo que entiende imparable tendencia dominante en la legislación de todos los países hacia la incorporación de nuevos tipos penales, así como a una agravación de los existentes, y a una mayor rigurosidad presencial de la pena de prisión que puede ubicarse en el marco general de la restricción o la reinterpretación de las garantías clásicas del Derecho penal sustantivo y del Derecho procesal penal ${ }^{27}$. Expansionismo que, sin embargo, motiva otro consenso doctrinal sobre la valoración crítica de la eficacia de la pena de prisión basado en dos seleccionados fundamentos esenciales para la crítica: a) la constatación de que el incremento del uso de la prisión no ha impedido el incremento de la criminalidad; b) el encarcelamiento no es una pena que afecta solamente al individuo condenado sino que arrastra a la familia cuando aquél es el sustento de ésta, como sucede en la mayoría de los casos de la población carcelaria $^{28}$.

\footnotetext{
${ }^{26}$ VAN ZYL SMIT, Dirk-SNACKEN, Sonja. Principios...cit., pág. 149.

${ }^{27}$ Por ejemplo Zaffaroni señala que en las últimas décadas se ha insistido en todo el mundo en aumentar la frecuencia de la prisión, fundamentalmente en Estados Unidos, como país referencia de cambio de perspectiva de la política criminal de la resocialización a la retribución enmascarada en la prevención general. ZAFFARONI, Eugenio Raúl. Manual de Derecho Penal. Parte General. Buenos Aires, 2005, pág. 702
}

${ }^{28}$ Vid., en esta línea: BENITO DURÁ, Muricio. Sistemas penitenciarios y alternativas en Iberoamérica. Análisis a partir de la situación de la criminalidad y las políticas criminológicas. Valencia, 2009, pág. 259. El autor añade, además, en semejante idea de efectos negativos de la pena de prisión: es un elemento desbaratador de la familia, la edad de los privados de libertad supone la inmovilización de un sector importante de la población activa de un país que afecta a su capacidad de crecimiento, tiene devastadores consecuencias tanto para la población penitenciaria como para la población en general al constituirse en foco de enfermedades infecto contagiosas, hacinamiento y efectos negativos de él, elevado costo, contrasentido que supone querer educar o reeducar a una persona para la sociedad, manteniéndola aislada de la misma durante años (pág. 260). 
Como se ha indicado, la utilización abusiva de la pena de prisión, y en consecuencia los discutibles éxitos de las alternativas a ella, sobre todo en la privación de libertad de media y larga duración, también parece una constante, sobre todo en determinados países. En dicho sentido, no han faltado las valoraciones más o menos radicalizadas. Intensa e interesante es la de Zaffaroni que llega a calificar la situación de fracaso de las ideologías de la resocialización y todo el conjunto de teorías preventivas especiales positivas, que coincide con la crisis del Estado providente, ante lo que resulta que en la realidad la prisión se convierte en un mero local de depósito de seres humanos deteriorados. "Se trata de una tendencia genocida que, en definitiva, se afilia a la prevención especial negativa, es decir, a la idea de la prisión como una eventual pena de muerte" 29 . Las radicalizadas precisiones del autor argentino necesitan ser limitadas, pero ponen de manifiesto una determinada concepción absolutamente crítica del desarrollo penitenciario; aunque el propio escritor las relativiza al añadir, a continuación, su percepción de que en pocas décadas la frecuencia de la prisionización disminuya debido al desarrollo tecnológico del control electrónico de conducta ${ }^{30}$; una variable, sin duda, de cierto atractivo pero insuficiente para pilotar un cambio real de la situación descrita en torno a la pena de prisión.

De cualquier manera, se llegue a la interpretación que sea, la realidad es la vitalidad de la pena de prisión, su extensión y su especial importancia como mecanismo de crecimiento del Derecho penal actual, a pesar de las puntuales oscilaciones que puedan haber en su aplicación concreta en un determinado período de tiempo y de las indicaciones programáticas tanto de Naciones Unidas como de la Unión Europea. Semejante oleaje expansionista ha llegado también con fuerza, con demasiada, a España en los últimos años. Con rotundidad, en este sentido, se manifestó Tellez Aguilera que al hilo de la criticable, pero ya casi lejana en el tiempo, Ley Orgánica $7 / 2003$, de 30 de junio, de medidas de reforma para el cumplimiento íntegro y efectivo de las penas -que, en mi opinión, introdujo negativos criterios retribucionistas y es una clara muestra de descoordinación y de oportunismo legislativo ${ }^{31}$; pero que, sin embargo, lo que es peor, supuso, así lo pienso, una muestra referencial de la nueva política

\footnotetext{
${ }^{29}$ ZAFFARONI, Eugenio Raúl. Manual de Derecho Penal. Parte General. Buenos Aires, 2005, pág. 702. ${ }^{30} \mathrm{Ibd}$.

${ }^{31}$ Vid., con mayor detenimiento: MORILLAS CUEVA, Lorenzo. Valoración...cit., págs. 44 y ss.
} 
criminal involucionista que se estaba diseñando en nuestro país haciendo, sus responsables, oídos sordos a coherentes y alternativas propuestas político-criminales de la Comisión de expertos en aquél momento creada precisamente para diseñar una planificada política criminal, como así se hizo, racional, garantista, respetuosa con los principios básicos del Estado social y democrático de Derecho, que precisamente por ello no tuvo especial éxito en las instancias del poder decisorio de aquél tiempo-, generaliza con acierto la situación que se vive a nivel de muchos Estados al poner de relieve cómo sobre la hipótesis del alejamiento del bagaje antirretribucionista, que floreció desde finales de los años setenta, por parte de los países de la Unión Europea por influencia de la política criminal americana cada vez más distanciada de los presupuestos preventivo-especiales, se constituye un neoconservadurismo penal que encuentra, amparado también por la crisis de la ideología del tratamiento penitenciario, un importante factor coadyuvante: la dramática visión que del fenómeno criminal dan los medios de comunicación que se traduce, por su intensidad y frecuencia, en un incremento de la alarma social y un endurecimiento progresivo de la represión penal ${ }^{32}$.

No son ajenas tampoco a estas valoraciones y al avance expansionista del Derecho penal en España, el propio Código penal de 1995 y, sobre todo, las destacadas reformas operadas por las Leyes Orgánicas 7/2003, de 30 de junio, de medidas de reforma para el cumplimiento íntegro y efectivo de las penas, ya citada; 11/2003, de 29 de septiembre, de medidas concretas en materia de seguridad ciudadana, violencia doméstica e integración social de los extranjeros; 15/2003, de 25 de noviembre, por la que se modifica la Ley Orgánica 10/1995, de 23 de noviembre, del Código penal; 20/2003, de 23 de diciembre, de modificación de la Ley Orgánica del Poder Judicial y del Código Penal; 1/2004, de 28 de diciembre, de Medidas de Protección Integral contra la Violencia de Género; 15/2007, de 30 de noviembre, por la que se modifica la Ley Orgánica 10/1995, de 23 de noviembre, del Código Penal en materia de seguridad vial; e, incluso, 5/2010, de 22 de junio, por la que se modifica la Ley Orgánica 10/1995, de 23 de noviembre, del Código Penal. Si bien, a alguna de ellas, no se les puede negar objetivos aciertos en sus contenidos, manifiestan una clara tendencia hacia presupuestos de expansión, que, en ocasiones, resultan sumamente discutibles cuando no peligrosos y desconcertantes científicamente. Una nueva prueba del talante de nuestro legislador, sea

32 TÉLLEZ AGUILERA, Abel. "La Ley de cumplimiento integro y efectivo de las penas: una nota de urgencia”. La Ley, núm 5837, 14 de agosto de 2003, págs. 2-3. 
cual sea el momento y el color de su mayoría parlamentaria, es el Proyecto de Código penal 2013 de acelerada tramitación parlamentaria que si las previsiones son exactas podría convertirse en ley en el mes de abril de 2015 y que intensifica la línea expansionista en los diversos niveles normativos del Texto punitivo, con especial intensidad en relación a la pena de prisión, entre la que incluye la discutible pena de prisión permanente revisable.

Y todo ello en un momento en el que parece detectarse, en los últimos años, una leve pero progresiva disminución de la aplicación de la pena de prisión o, por lo menos, de los índices de encarcelamiento en nuestros Centro penitenciarios. Veamos algunas muestras estadísticas de esta panorámica.

Evolución de la población reclusa en España (2005-2014)

\begin{tabular}{|l|l|l|l|l|l|l|l|l|l|}
\hline 2005 & 2006 & 2007 & 2008 & 2009 & 2010 & 2011 & 2012 & 2013 & 2014 \\
\hline 60.707 & 63.248 & 65.812 & 70.485 & 75.774 & 76.108 & 72.564 & 70.126 & 68.440 & 65.020 \\
\hline
\end{tabular}

Elaboración propia con datos de Instituciones Penitenciarias. Media de cada año.

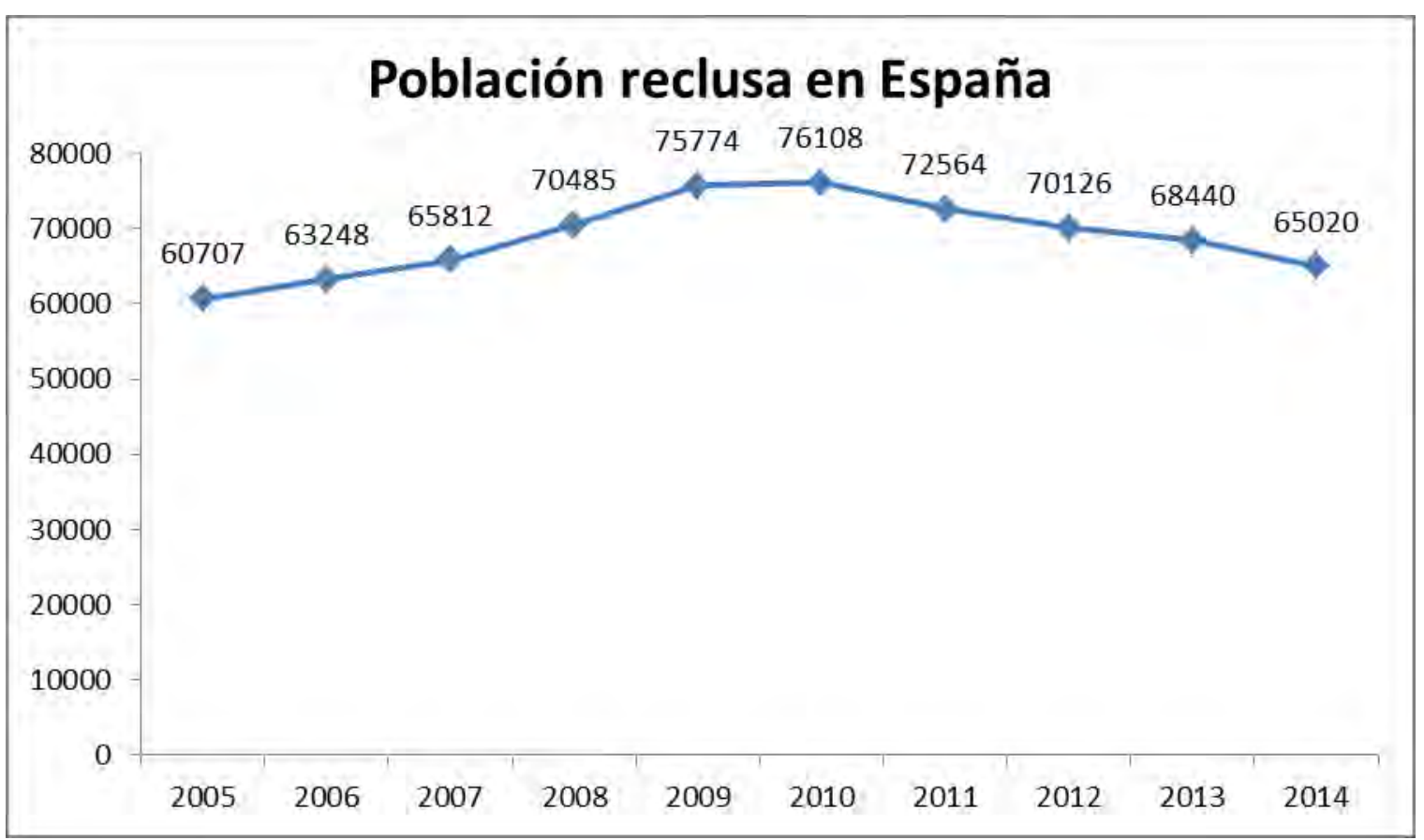


El gráfico y la tabla nos muestran dos dimensiones diferenciadas en la trayectoria más reciente de la aplicación real de la pena de prisión en España y la consecuente cuantificación de la población reclusa en nuestros Centros penitenciarios. La primera valoración es con respecto al sexenio comprendido entre 2005, año en el que se pudo empezar a sentir las incidencias de la reformas llevadas a cabo en 2003 y 2004 en el Texto punitivo español ${ }^{33}$ que producen una subida progresiva de dicha población tocando techo precisamente en el año 2010, con la cifra más alta de la última década 76.108 internos lo que supone un diferencial $+20,24 \%$, en los susodichos 6 años-; el siguiente quinquenio tiene una trayectoria descendente, a pesar de la todavía importante cifra y porcentaje de internos a la cabeza prácticamente de la Europa de los quince. Se produce, en contra del anterior, un decrecimiento progresivo de la población reclusa en nuestro país que puede ser tasado en un diferencial de $-14,57 \%$ desde el año 2010 al 2014, con parciales 4,66\% -2011- 3,36\% -2012-, 2,41\% -2013-, 5,00\% -2014-. Singularmente relevante es la bajada producida en el año 2011, en el que se perciben los primeros resultados de la reforma 5/2010 del Código penal, en especial determinados tipos que, en contra corriente a la línea general, son atenuados, como es el caso de algunos delitos contra la salud pública. En concreto el artículo 368 sufre una importante modificación que afecta significativamente al encarcelamiento por esta tipología desde una doble perspectiva: a) con la reducción del máximo de pena a seis años cuando se tratare de productos o sustancias que causen grave daño a la salud -ahora la pena es de tres a seis años y antes de tres a nueve años; b) con la incorporación de una atenuación de pena -inferior en grado- en atención a la escasa entidad del hecho y de las circunstancias personales del culpable, lo que da un amplio margen al Juez o Tribunal no solo para rebajar la pena sino asimismo para utilizar la suspensión o sustitución de pena de prisión señalada. Cierto es que cuantitativamente la modificación indicada no conlleva un menor número de condenados ${ }^{34}$ pero sí de ingresos en prisión.

\footnotetext{
${ }^{33}$ Ya predecía Díez Ripollés en su estudio sobre las reformas penales hasta 2003, aunque publicado con posterioridad, que el uso desproporcionado que advierte de la pena de prisión desde el año 2000 a 2004, se acentuaría en cuanto se sintieran plenamente los efectos de las reformas de 2003, para calificar el sistema de penas de "anticuado, injusto e ineficaz". Los datos posteriores parece avalar semejante afirmación, al menos hasta 2010. DIEZ RIPOLLÉS. José Luis. "La evolución del sistema de penas en España: 1975-2003”. En Revista Electrónica de Ciencia Penal y Criminología. 2006, pág. 23.
}

${ }^{34}$ Condenados por delitos contra la salud pública

\begin{tabular}{|l|l|l|l|l|l|}
\hline 2008 & 2009 & 2010 & 2011 & 2012 & 2013 \\
\hline 11.713 & 12.575 & 12.702 & 12.099 & 13.143 & 13.441 \\
\hline
\end{tabular}


De todas formas aunque estos últimos datos son a tener en cuenta y requieren atención en cuanto a la tendencia reduccionista de las masificadas cifras de internos en los Centros penitenciarios españoles, cierto es, al mismo tiempo, que incluso los datos de 2014 son todavía muy superiores a los reflejados en el año $2005^{35}$, y bastantes más a los anteriores a este año:

\section{Evolución de la población reclusa en España (1996-2004)}

\begin{tabular}{|l|l|l|l|l|l|l|l|l|}
\hline 1996 & 1997 & 1998 & 1999 & 2000 & 2001 & 2002 & 2003 & 2004 \\
\hline 44.312 & 43.453 & 44.747 & 45.384 & 45.309 & 46.594 & 50.537 & 54.497 & 58.655 \\
\hline
\end{tabular}

Elaboración propia con datos de Instituciones Penitenciarias. Media de cada año.

Como puede comprobarse en el tiempo de publicación y entrada en vigor del Código penal de 1995, en cuyo año inmediato, 1996, los números de población reclusa estaban en cifras bastantes bajas -44.312- van subiendo progresivamente hasta llegar a un $24.46 \%$, de aumento entre 1996 y 2004 . Números, en todo caso, muy inferiores a los actuales a pesar de la reducción experimentada. Mucho me temo que la situación valorada desde 2010 a 2014 sea una simple tregua que se romperá con estruendo con la entrada en vigor del proyectado Código penal reformado de 2015. Dicho lo anterior es necesario matizar la presencia y utilización expansionista de la pena de prisión en nuestro texto punitivo. Sobre dos tablas y un gráfico ${ }^{36}$ voy a presentar las diversas

Elaboración propia con datos del INE

${ }^{35}$ Cid Moliné que parte de la base, acertada, de un mayor rigor punitivo del Código de 1995 que no solo, entre otras hipótesis, aumentó las penas de algunos delitos de frecuente realización, sobre todo patrimoniales, y suprimió la redención de penas por el trabajo da como explicación de la reducción de la entradas en el prisión en el periodo 1996-2005, las cuatro posibles de reducción de condenas penales por delitos, reducción del número de condenas a penas privativas de libertad, aumento del uso de la suspensión y sustitución de penas privativas de libertad, reducción del uso de la prisión preventiva. CID, José. "El incremento de la población reclusa en España entre 1996-2006: Diagnósticos y remedios" En Revista Española de Investigación Criminológica. No6, 2008, págs. 7 y ss. Vid., asimismo: GRUPO DE ESTUDIOS DE POLÍTICA CRIMINAL. Una propuesta alternativa ...cit., págs. 12 y ss.

36 Semejantes tablas y gráfico son de elaboración propia dentro del Proyecto "La aplicación de las alternativas a la pena de prisión en España”, bajo la dirección de Morillas Cueva- Barquín Sanz y dentro de un Convenio específico de colaboración entre la Universidad de Granada, a través del Instituto 
opciones y presencias de las penas en nuestro Texto punitivo vigente. La primera de ellas hace referencia al análisis de cuatro seleccionadas por su incidencia en relación a la de prisión que es la primera a analizar en cuanto a su tratamiento como sustitutivos de ésta, pero aquí en su aspecto más autónomo. Sobre la presentación de dichas penas, las variables son: no inclusión en el precepto correspondiente, presencia como pena única, como pena acumulativa y como pena alternativa de otras expresamente también detalladas en el tipo. Se atiende a la frecuencia y al \%.

Formas de presentación de las diferentes penas en el CP

\begin{tabular}{|c|c|c|c|c|c|c|}
\hline & & \multicolumn{4}{|c|}{ Formas de presentación de la pena } & \multirow[b]{2}{*}{ Total } \\
\hline & & no & única & $\begin{array}{c}\text { acumulati } \\
\text { va }\end{array}$ & $\begin{array}{c}\text { alternativ } \\
\text { a }\end{array}$ & \\
\hline \multirow[b]{2}{*}{ Prisión } & Fr. & 223 & 286 & 268 & 61 & 838 \\
\hline & $\%$ & 26.61 & 34.13 & 31.98 & 7.28 & 100.0 \\
\hline \multirow[b]{2}{*}{ Multa } & Fr. & 444 & 77 & 234 & 83 & 838 \\
\hline & $\%$ & 52.98 & 9.19 & 27.92 & 9.90 & 100.0 \\
\hline \multirow[b]{2}{*}{ Localización permanente } & Fr. & 817 & 1 & 1 & 19 & 838 \\
\hline & $\%$ & 97.49 & 0.12 & 0.12 & 2.27 & 100.0 \\
\hline \multirow{2}{*}{$\begin{array}{l}\text { Trabajos beneficio } \\
\text { comunidad }\end{array}$} & Fr. & 820 & 0 & 0 & 18 & 838 \\
\hline & $\%$ & 97.85 & 0.00 & 0.00 & 2.15 & 100.0 \\
\hline
\end{tabular}

Elaboración propia con datos del INE

Andaluz Interuniversitario de Criminología (Sección Granada). En concreto aquellas y el gráfico fueron realizados dentro del Capítulo "Análisis de las penas del Código penal vigente desde una perspectiva estadística" por Barquín Sanz-Luna del Castillo. La aplicación de las alternativas...cit., págs. 94 y 96 a 98. 
De las cuatro penas seleccionadas por las razones antes indicadas, la de prisión es la que tiene una mayor presencia notablemente más que las demás, únicamente superada como alternativa a otras penas dentro del tipo correspondiente por la multa 9.90\% para esta (83 casos), 7.28 para aquella (61). En el cómputo total solo en el $26.61 \%$ de las hipótesis no es utilizada -frente al $52.98 \%$ para la multa- por lo que en el resto $-73.39 \%$ - está incorporada ya sea como única -en un porcentaje verdaderamente amplio -34.13\%; la multa solo un 9.19\%-, como acumulada $-31.98 \%$. Aquí es donde la multa se le aproxima más con un $27,92 \%$, pero en todo caso incluso en la acumulación la pena de referencia es la de prisión-, o alternativa en los niveles antes examinados para ambas.

Por otro lado, la presencia de la localización permanente y los trabajos en beneficio de la comunidad, entiendo que importantes dentro de una política criminal reduccionista de la pena de prisión, como posibles sustitutivos directos de ésta, es mínima en el Código penal vigente, -al margen del juego que puedan dar como sustitutivos penales en clave de sustitución de las penas privativas de libertad únicamente un $2.27 \%$ para la primera y un $2.15 \%$ para la segunda.

En todo caso lo que queda especialmente nítido es la exagerada utilización de la pena de prisión en el Texto punitivo, alarmantemente utilizada en supuestos en los que se nos antoja como innecesaria ${ }^{37}$.

La segunda se asienta sobre parecidos parámetros pero extendida a todas las penas sobre la base de la frecuencia en general y el \% de preceptos en los que cada pena está presente

\footnotetext{
${ }^{37}$ Con mayor extensión, Vid.: Ibd., págs. 94-96.
} 
Diferentes penas vinculantes en los diferentes preceptos

\begin{tabular}{|c|c|c|}
\hline & Fr. & $\begin{array}{c}\% \text { preceptos en } \\
\text { los que se } \\
\text { presenta }\end{array}$ \\
\hline prisión & 554 & 66.11 \\
\hline multa & 311 & 37.11 \\
\hline inhabilitación o suspensión & 251 & 29.95 \\
\hline prisión o multa & 57 & 6.80 \\
\hline localización permanente o multa & 17 & 2.03 \\
\hline privación de armas & 13 & 1.55 \\
\hline privación de conducir & 10 & 1.19 \\
\hline privación de subvenciones & 10 & 1.19 \\
\hline prisión o trabajos en beneficio de la comunidad & 7 & 0.84 \\
\hline trabajos en beneficio de la comunidad o multa & 5 & 0.60 \\
\hline privación de patria potestad & 5 & 0.60 \\
\hline comiso & 5 & 0.60 \\
\hline prisión o multa o trabajos en beneficio de la comunidad & 3 & 0.36 \\
\hline localización permanente & 2 & 0.24 \\
\hline localización permanente o trabajos beneficio comunidad & 2 & 0.24 \\
\hline privación de acceso a concurso público & 2 & 0.24 \\
\hline libertad vigilada & 2 & 0.24 \\
\hline $\begin{array}{l}\text { o bien prisión, o bien multa y trabajos beneficio } \\
\text { comunidad }\end{array}$ & 1 & 0.12 \\
\hline restauración & 1 & 0.12 \\
\hline
\end{tabular}


De nuevo en esta tabla se pone de manifiesto la preponderancia de la pena de prisión en relación al resto de las penas. Ésta se manifiesta como la más utilizada cuantitativamente sobre una frecuencia de 554 lo que significa un $66.11 \%$ del total. A lo que hay que añadir la alternancia prisión o multa que supone otro $6,80 \%$, prisión o trabajos en beneficio de la comunidad, $0.84 \%$, prisión o multa o trabajos en beneficio de la comunidad, 0,36, o prisión o multa y trabajos en beneficio de la comunidad, 0.12 , que supone un total de posibilidad de aplicación de la susodicha pena de prisión de un $74.23 \%$, cerca de $2 / 3$ de presencialidad. Es seguida a cierta distancia por la de multa, con un $37.11 \%(+6,80 \%+2.03 \%+0.60 \%+0.36 \%+0.12 \%)=47.02 \%)$, inhabilitaciones $\mathrm{o}$ suspensiones, 29,50\%. Todas las demás se sitúan en uno niveles mínimos que no sobrepasan el $1.55 \%$, lo que vuelve a poner de manifiesto cuál es la pena referencia a todos los efectos para nuestro legislador ${ }^{38}$.

De manera posiblemente más gráfica en la idea de una mayor concreción informativa, pero con parecidos resultados, utilizo el siguiente gráfico:

\section{Porcentajes de preceptos en los que se presentan las diferentes penas}

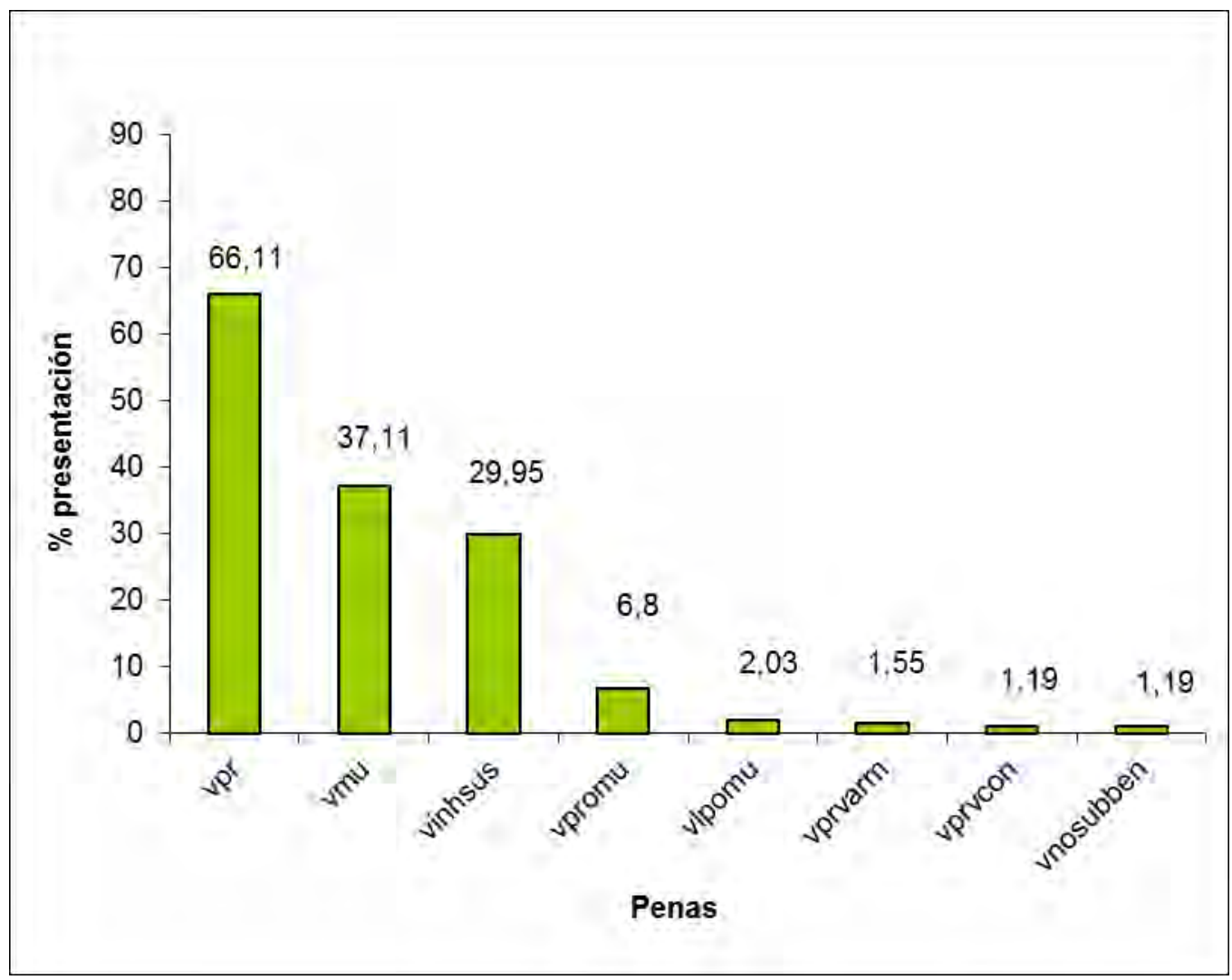

\footnotetext{
${ }^{38}$ Con mayor extensión, vid:: Ibd., págs. 98-99.
} 


\section{Elaboración propia.}

$\mathrm{V}=$ penas vinculantes; $\mathrm{vpr} \equiv$ prisión; $\mathrm{vmu} \equiv$ multa; $v$ inhsus $\equiv$ inhabilitación o suspensión; vpromu $\equiv$ prisión o multa; vlpomu $\equiv$ localización permanente o multa; vprvarm $\equiv$ privación del derecho a portar armas; vprvcon三 privación del derecho a conducir vehículos; vnosubben” privación del derecho a recibir subvenciones.

Como añadido a semejantes datos que ya por sí solos ponen de manifiesto la extensión con que en la realidad de nuestro Código penal y en el desarrollo penitenciario se muestra el uso de la reiterada pena de prisión, cabe completar esta visión interna valorativa con las cifras de penas en condenas para lo que he seleccionado los años de 2011 a 2013, es decir a partir de la reforma 5/2010.

Estadísticas penas en condenas. Años 2011-2013

\begin{tabular}{|c|c|c|c|c|c|c|}
\hline & \multicolumn{2}{|c|}{2011} & \multicolumn{2}{|c|}{2012} & \multicolumn{2}{|c|}{2013} \\
\hline Total & 551.387 & $100 \%$ & 557.793 & $100 \%$ & 608.901 & $100 \%$ \\
\hline 1.Penas privativas de libertad & 143.368 & $26 \%$ & 144.542 & $25,9 \%$ & 154.480 & $25,37 \%$ \\
\hline 1.1. Prisión & 138.713 & $24,6 \%$ & 142.444 & $25,5 \%$ & 153.950 & $25,28 \%$ \\
\hline $\begin{array}{l}1.2 \text { Responsabilidad penal } \\
\text { subsidiaria }\end{array}$ & 7.202 & $1,3 \%$ & 1.667 & $0,3 \%$ & 41 & $0,01 \%$ \\
\hline 1.3 Localización permanente & 400 & $0,1 \%$ & 399 & $0,1 \%$ & 460 & $0,08 \%$ \\
\hline 1.4 Arresto fin de semana & 53 & $0,0 \%$ & 32 & $0 \%$ & 9 & $0,001 \%$ \\
\hline $\begin{array}{l}\text { 2. Penas privativas de otros } \\
\text { derechos }\end{array}$ & 300.970 & $54,6 \%$ & 302.688 & $54,3 \%$ & 330.542 & $54,29 \%$ \\
\hline 2.1 Inhabilitación absoluta & 594 & $0,1 \%$ & 537 & $0,1 \%$ & 608 & $1,00 \%$ \\
\hline $\begin{array}{l}2.2 \text { Inhabilitación especial para } \\
\text { empleo }\end{array}$ & 93.566 & $17 \%$ & 103.619 & $18,6 \%$ & 111.335 & $18,28 \%$ \\
\hline
\end{tabular}




\begin{tabular}{|l|c|c|c|c|c|c|}
\hline $\begin{array}{l}\text { 2.3 Suspensión empleo o cargo } \\
\text { público }\end{array}$ & 284 & $0 \%$ & 158 & $0 \%$ & 123 & $0,02 \%$ \\
\hline $\begin{array}{l}\text { 2.4 Privación del derecho de } \\
\text { conducir }\end{array}$ & 79.453 & $14,4 \%$ & 74.145 & $13,3 \%$ & 72.197 & $11,86 \%$ \\
\hline $\begin{array}{l}\text { 2.5 Privación derecho tenencia } \\
\text { de armas }\end{array}$ & 26.966 & $5,2 \%$ & 28.223 & $5,1 \%$ & 28.578 & $4,69 \%$ \\
\hline $\begin{array}{l}\text { 2.6 Privación derecho a } \\
\text { residir..... }\end{array}$ & 709 & $0,1 \%$ & 486 & $0,1 \%$ & 399 & $0,07 \%$ \\
\hline $\begin{array}{l}\text { 2.7 Prohibición de aproximarse } \\
\text { a víctima }\end{array}$ & 30.707 & $5,6 \%$ & 30.516 & $5,5 \%$ & 32.378 & $5,32 \%$ \\
\hline $\begin{array}{l}\text { 2.8 Prohibición de } \\
\text { comunicarse.... }\end{array}$ & 10.265 & $1,9 \%$ & 10.934 & $2 \%$ & 28.155 & $4,62 \%$ \\
\hline $\begin{array}{l}\text { 2.9 Trabajos en beneficio de la } \\
\text { comunidad }\end{array}$ & 104.783 & $19 \%$ & 108.373 & $19,4 \%$ & 121.971 & $20.03 \%$ \\
\hline 3. Multa & 56.426 & $10,2 \%$ & 54.070 & $9,7 \%$ & 56.769 & $9,32 \%$ \\
\hline $\begin{array}{l}\text { 4. Expulsión del territorio } \\
\text { nacional }\end{array}$ & $0,4 \%$ & 2.190 & $0,4 \%$ & 1.928 & $0,32 \%$ \\
\hline
\end{tabular}

\section{Elaboración propia. Datos INE.}

Lo primero a indicar es la estabilidad de los datos en los tres años estudiados para cada pena con 1 punto arriba/abajo al menos en las tres principales. En segundo, la ficticia cuantificación de las cifras relativas a las penas privativas de otros derechos, con una media del 54.4\%, lo que supone un relevante despegue con referencia a las demás, incluida la de prisión, pero sucede que bajo este epígrafe se incluyen hasta 9 modalidades de diversa naturaleza en cuanto a su aplicación -la inhabilitación especial para el empleo con una media de 17,96\%, privación del derecho a conducir con 13,18\% y trabajos en beneficio de la comunidad con 9,74. En tercer lugar y con esta perspectiva, las cinco más usadas en las condenas son: prisión, multa y las tres indicadas privativas de otros derechos. Puede sorprender, al menos inicialmente, en cuarto lugar la exigua diferencia entre la prisión y la multa e incluso las demás aludidas entre las cinco primeras, lo que supone una cierta disfuncionalidad entre su expansiva presencia en el Código penal, el número proporcionalmente importante de internos en las prisiones 
españolas, aunque a la baja en los tres años en examen, y el dato expuesto en este apartado.

Explicadas con anterioridad las causas del mínimo descenso de la población penitenciaria queda valorar esta nueva posible disfuncionalidad entre sentencias con pena de prisión y realidad de la pena en nuestro Ordenamiento jurídico penal. Entiendo que en clave judicial se está optando por utilizar en los supuestos con penas alternativas, donde esté, entre ellas, la de prisión, las otras sanciones punitivas, 7.28\%, pero en infracciones penales de frecuente comisión -un ejemplo a resaltar es el de los delitos contra la seguridad vial (en el año 2013 hubo 101.271 condenas por estas tipologías sobre 275.196 como total, lo que supone un $36,79 \%$ de éste), en los que es poco frecuente el uso de la privación de libertad-. Semejante apreciación viene corroborada por el porcentaje de sentencias que incluyen los trabajos en beneficio de la comunidad media de los tres años 9.73\%- frente a su presencia como pena en los diversos tipos penales $-2.15 \%$-. Tendencia totalmente inversa a la de la pena de prisión. Además, y por otra parte, que las condenas con pena de prisión son de duración temporal alta y con permanencia en los Centros penitenciarios más continuada y más propicia al cumplimiento integro de dichas penas, sin que ello obvie la aplicación de beneficios penitenciarios. Es decir, el tiempo medio de permanencia en prisión ha aumentado sensiblemente en relación a situaciones anteriores al año 2005, pero por delitos más seleccionados.

Junto a los parámetros indicados es necesario completar este sintético mapa relacionado con el uso de la pena de prisión y el encarcelamiento atendiendo a algunas cuestiones de Derecho comparado. Lo he de situar en los años 2013 y 2014, como necesaria elección temporal de muestra, en enero de cada uno de ellos, sobre la selección de la Europa de los quince y con los ítems del total de número de internos en los Centros penitenciarios, el total de capacidad de estos, la densidad -número de internos por unidad de superficie- de la prisión por 100 plazas y la ratio de la población penitenciaria por cada 100.000 habitantes. 
Variables de población reclusa y capacidad de los Centros penitenciarios (2013-2014)

\begin{tabular}{|c|c|c|c|c|c|c|c|c|}
\hline \multirow[t]{2}{*}{ País } & \multicolumn{4}{|c|}{ 1-1-2013 } & \multicolumn{4}{|c|}{$1-1-2014$} \\
\hline & Presos & Capacidad & Densidad & Ratio & Presos & Capacidad & Densidad & Ratio \\
\hline Alemania & 65.889 & 77.578 & 84.9 & 80.3 & 62.632 & 76556 & 81.8 & 77.5 \\
\hline Austria & 8.273 & 8.650 & 95,6 & 97,9 & 8.862 & 8.636 & 97,1 & 104,2 \\
\hline Belgica & 12.128 & 9.351 & 124.4 & 108.6 & 12.945 & 9.715 & 118.8 & 115.5 \\
\hline Dinamarca & 3.820 & 4.103 & 93,1 & 68,2 & 3.774 & 4.160 & 90,7 & 67,1 \\
\hline España & 68.618 & 77.955 & 88 & 147 & 66.785 & 77.895 & 85.7 & 143.6 \\
\hline Finlandia & 3.134 & 3.089 & 96,9 & 57,8 & 3.011 & 3.089 & 93,2 & 55,2 \\
\hline Francia & & & & 98 & 77.883 & 57518 & 116.6 & 118.3 \\
\hline Grecia & & & & 111 & 12.693 & 9.886 & $128,4 \%$ & $115,5 \%$ \\
\hline Holanda & 10.817 & 12.491 & 86.6 & 64.6 & 10.224 & 12.491 & 81.9 & 60.8 \\
\hline $\begin{array}{c}\text { Inglaterra/ } \\
\text { Gales }\end{array}$ & 83.757 & 90.442 & 92.8 & 147.1 & 84.163 & 85.953 & 97.9 & 148 \\
\hline Irlanda & 4.086 & 4.574 & 89,5 & 89,0 & 3.987 & 4.274 & 93,3 & 86,6 \\
\hline Italia & 65.701 & 47.040 & 138.7 & 110.1 & 62.536 & 47.709 & 143.1 & 102.9 \\
\hline Luxemburgo & 656 & 711 & 92,3 & 122,2 & 701 & 711 & 98,6 & 127,5 \\
\hline Portugal & 13.614 & 12.077 & 112.7 & 129.8 & 14.284 & 12.167 & 117.4 & 137.0 \\
\hline Suecia & 5.878 & 6.984 & 84.2 & 61.5 & 5.525 & 6.563 & 84.2 & 57.3 \\
\hline
\end{tabular}

Elaboración propia con datos del Council of Europe Annual Penal Statistics (SPACE I y SPACE II) y World Prison Population List (tenth edition). Roy Walmsley. ICPS. $2013^{39}$

\footnotetext{
${ }^{39}$ En verde las cifras utilizadas de las estadísticas de World Prison Population List. El resto de SPACE.
} 
Los datos recogidos reiteran la tendencia decreciente de internos ${ }^{40}$ en España, pero manteniéndose nuestro país en los puestos de cabeza, en ratio de población penitenciaria por 100.000 habitantes, únicamente superada por muy poco por Inglaterra/Gales de fuerte tradición en cuanto a liderar listas de encarcelamientos, propiciado por el peculiar sistema anglosajón - muy a distancia, sin embargo, de la exorbitada cifra de EEUU, 716 por 100.000 habitantes-. Destacan, en sentido contrario, los países nórdicos, Suecia y Finlandia, respectivamente con 61.5/57.3 y 57.8/55.2 y asimismo Holanda, 64.6/60.8, Dinamarca 68.2/67.1. A pesar de la situación preeminente de España en dicha ratio, está, no obstante, en los primeros puestos en cuanto a capacidad de sus Centros penitenciarios, únicamente superada por Alemania, Holanda y Suecia.

El sistema español hay que valorarlo en su doble dimensión competencial: la de la Administración del Estado y la Administración catalana. En ambos años, y con los mismos parámetros y fuentes, estos son los datos diferenciados.

Variables de población reclusa y capacidad de los Centros penitenciarios (2013-2014). Administración Estatal y Cataluña

\begin{tabular}{|c|c|c|c|c|c|c|c|c|}
\hline & \multicolumn{5}{|c|}{2013} & \multicolumn{3}{c|}{2014} \\
\hline España \\
(total) & Presos & Capacd. & Densid. & Ratio & Presos & Capacd & Densid. & Ratio \\
77.955 & 88 & 147 & 66.785 & 77.895 & 85.7 & 143.6 \\
\hline $\begin{array}{c}\text { España (Ad. } \\
\text { Estatal) }\end{array}$ & 58.556 & 66.924 & 87.5 & 148.0 & 56.968 & 66.864 & 85.2 & 145.4 \\
\hline $\begin{array}{c}\text { España } \\
\text { (Cataluña) }\end{array}$ & 10.62 & 11.031 & 91.2 & 133.2 & 9.818 & 11.031 & 89 & 132.5 \\
\hline
\end{tabular}

Como puede advertirse en Cataluña la densidad de número de internos por 100.000 habitantes es sensiblemente inferior a la del resto del Estado, lo que es una constante en todos los años examinados. Sin embargo, en relación a la capacidad de los Centros penitenciarios es superior a la de la Administración estatal.

\footnotetext{
${ }^{40}$ No es criterio general en todos los países examinados, pues en algunos de ellos las cifras totales y parciales reflejan un aumento en el año 2014. Así, por ejemplo: Austria, Bélgica, Inglaterra/Gales, Luxemburgo, Portugal.
} 
Por último, las cifras de población penitenciaria/ratio por 100.000 habitantes en la evolución de nuestro país muestran igualmente las oscilaciones del número de internos y, en consecuencia, la aplicación real de la pena de prisión:

\section{Evolución en España de la tasa de encarcelamiento por 100.000 habitantes}

\begin{tabular}{|l|l|l|l|l|l|l|}
\hline Año & 1997 & 1998 & 1999 & 2000 & 2001 & 2002 \\
\hline $\begin{array}{l}\text { Tasa por } \\
100.000\end{array}$ & 113 & --- & 114 & 114 & 117 & 126,2 \\
\hline Año por & 135,8 & 140,3 & 142,4 & 146,1 & 150.2 & 157 \\
\hline $\begin{array}{l}\text { Tasa } \\
100.000\end{array}$ & 2003 & 2004 & 2005 & 2006 & 2007 & 2008 \\
\hline $\begin{array}{l}\text { Año por } \\
\text { 165 }\end{array}$ & 160 & 159 & --- & 147 & 143.7 \\
\hline $\begin{array}{l}\text { Tasa } \\
100.000\end{array}$ & 2010 & 2011 & 2012 & 2013 & 2014 \\
\hline
\end{tabular}

Elaboración propia con datos del Council of Europe Annual Penal Statistics. SPACE II.

Dicha evolución es, como no puede ser de otra manera, muy coincidente con el aumento/disminución del analizado número de internos en las prisiones españolas. En el momento de la entrada en vigor del Texto punitivo la tasa y el número de internos caben ser calificados como moderadamente altos. A partir del año 1996 se produce un continuado ascenso también en línea de mesura. Es en el año 2003 y siguientes en los que se produce una verdadera explosión expansionista que llega en su avance hasta 2009 con un 165 por 100.000. Desde ese año hasta la fecha la disminución de las tasas y del número de internos es una realidad que llega hasta el año en curso y que puede significar el comienzo de una política criminal reduccionista en la aplicación de la pena de prisión o. por el contrario, simplemente un movimiento coyuntural sin mayor trascendencia político criminal. La próxima y amplia reforma del Código penal será decisiva en uno $u$ otro sentido. Mucho me temo que en el segundo. 


\section{IV.- A MANERA DE CONCLUSIÓN}

De todo lo analizado y valorado a lo largo de este trabajo se llega en primer lugar a la conclusión de que pese al empeño de Naciones Unidas, de la Unión Europea y de otras Instituciones a nivel mundial sobre la utilización de las penas alternativas a la prisión, ésta sigue siendo la referencia esencial de los sistemas punitivos actuales en la mayoría de los países como lanzadera principal del continuado expansionismo del Derecho penal. En este sentido no han faltado autores que señalan que en Europa como en Estados Unidos ${ }^{41}$, se está poco a poco volviendo a la represión penal como medio para tratar los problemas sociales, con la creciente utilización del encarcelamiento como respuestas mayoritaria y sólidamente afianzada en su estructura ${ }^{42}$. Afirmación que me parece acertada al menos como planteamiento general.

En España la cuestión adquiere caracteres muy relevantes. Mientras la criminalidad española está a niveles especialmente bajos dentro de la estructura punitiva europea, las cifras de personas encarceladas, como hemos visto, se muestra en los primeros lugares dentro del marco europeo, incluso en los últimos años donde se detecta un tenue descenso sin que ello oculte los importantes números ofrecidos. Como antes he citado ya en 2006 Díez Ripollés calificó el sistema de penas en España de anticuado, injusto e ineficaz. La situación no ha cambiado significativamente, encontrándose en parámetros muy alejados de una concepción reduccionista de la pena de prisión, que implica una limitación de la población penitenciaria a través, además de otros mecanismos, de lo que se ha venido a denominar estrategia de puertas abiertas despenalización, minoración de la utilización y duración de la prisión preventiva, prioridad importante para una política criminal de esta naturaleza, y de la prisión para los condenados, fomento de las penas no privativas de libertad, encarcelamiento como ultima ratio- o de puertas cerradas- que los que se estimen periodos de detención versus encarcelamiento sean lo más breves posibles, con especial atención a la libertad condicional-, todo ello con el escrupuloso respeto a los derechos humanos de los reclusos ${ }^{43}$.

\footnotetext{
${ }^{41}$ En mi opinión más en Estados Unidos. Las cifras anteriormente expuestas son contundentes.

${ }^{42}$ En tal sentido, con recogida de otras opiniones doctrinales: SNACKEN, Sonja-VAN ZYL SMIT, Dirk. Principios...cit., págs.523 y ss.

${ }^{43}$ Con mayor amplitud, vid: SNACKEN, Sonja-VAN ZYL SMIT, Dirk. Principios...cit., págs. 150 y ss
} 
Se ha dicho y posiblemente con razón que en todos los países del mundo existen cárceles y que la pena de prisión es utilizada igualmente en todos los Códigos penales. No es mi intención en este escrito negar tal premisa, bien que me gustaría, pero ambas parecen una inevitable plaga social que tenemos que asumir, con cierta amargura, aunque eso sí como la ultima ratio de la ultima ratio que es la privación de libertad dentro de la que es el propio Derecho penal y sus imprescindibles principios garantistas.

En semejante sentido, la pena de prisión, como realidad empírica, así ha sido analizada en este trabajo, es el instrumento más demandado dentro del sistema penal, por su significado en una sociedad donde parece crecer la sensación de peligro, frecuentemente de manera no constatada, hasta convertirse en una hipotética sociedad de riesgo en la que se dan impulsivas reacciones a convicciones allanadas por influencias mediáticas y por determinadas ideologías que conducen al incremento de la alarma social y la permanente exigencia de un endurecimiento de los medios de reacción penal, lo que provoca la presencia prepotente cuantitativa y cualitativamente dentro del Texto punitivo de la prisión y, en su ejecución, del encarcelamiento. Situación comprometida por su expansionismo que parece no tener freno ni límite incluso con el acceso al poder en los más variados sistemas y gobiernos de grupos políticos con convicciones progresistas que por su vinculación ideológica más comprometida, en teoría, con acciones sociales pueden visualizarse como más implicados en un garantismo penal, con un derecho de la prevención, integrador socialmente y recuperador de los ciudadanos que delinquen sobre políticas sociales y criminales sustentadas en mecanismos alternativos que alejen, en la medida de lo posible, la comisión de delitos y el uso desmesurado de dicha pena, como sucede, esto último, puntualmente en nuestro sistema penal y preveo sucederá todavía con más intensidad en el futuro con la entrada en vigor de la reforma 2015, consolidación legal del criticado Proyecto 2103.

Afirmado esto, en línea de argumentación con lo narrado en este escrito, y en referencia a los parámetros esenciales proclamados por Naciones Unidas y la Unión Europea, sin especial éxito en su concreción legal en el derecho interno de sus países miembros, procede, en todo caso, apostar por una política criminal moderna $y$ planificada que no puede ser otra que la del reduccionismo punitivo, que aporte los mecanismos suficientes para desterrar las disfuncionalidades que la excesiva utilización de la pena de prisión muestra en los sistemas actuales y que lleve a los Ordenamientos 
jurídicos internos la prioridad de las penas y medidas no privativas de libertad para de este modo y con tal objetivo proporcionar diversificadas opciones diferentes a aquella que limiten, al máximo de lo posible, en esencia para las penas de corta y media duración y también para las de larga duración, en estas como mínimo el deber de los gobiernos de justificar necesariamente semejante encarcelamiento con la precisión de conseguir relevantes fines sociales en clave de bienes jurídicos fundamentales para la seguridad y la paz social cuya conculcación suponga tal negatividad de aquellas que no puedan ser protegidas por otros medios menos restrictivos de un derecho humano tan esencial como es el de la libertad personal. En definitiva, reducir la presencia de la pena de prisión y su aplicación para racionalizar, todavía con más intensidad, las políticas de justicia penal sobre el imprescindible soporte del respeto a los derechos humanos de todos los ciudadanos incluidos los condenados, las exigencias de justicia social sobre la trilogía garantista y aseguradora: delincuente-sociedad- víctima. Únicamente así se podrá legitimar en cierta medida la pena de prisión en el Estado social y democrático de Derecho- 